\title{
Electrodynamic Tether System Analysis Comparing Various Mission Scenarios
}

\author{
Keith R Fuhrhop*, Brian E. Gilchrist ${ }^{\dagger}$ \\ University of Michigan, Ann Arbor, MI., 48109
}

\begin{abstract}
This paper presents the theoretical analysis and modeling of an electrodynamic tether (EDT) system under an assortment of mission scenarios and physical constraints with a focus on comparing electron emission technologies used at one end of the tether. There are three different types of electron emitters considered: thermionic cathodes, field emitter arrays, and hollow cathodes. Each is evaluated for its potential use in three different system architectures: basic grounded-emitter, basic grounded-gate and series-bias system architectures. The overall results show how the efficiencies and power consumptions change depending on the mission objectives. We show what configurations yield the best performance under an array of constraints for both boosting and de-boosting tethers.
\end{abstract}

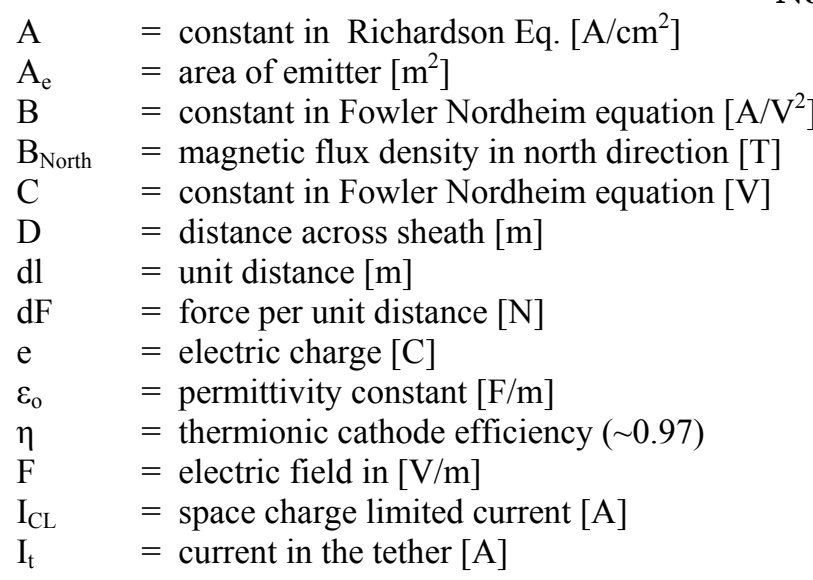

\section{Nomenclature}

$\mathrm{J}=$ current density $\left[\mathrm{A} / \mathrm{m}^{2}\right]$

$\mathrm{k}=$ Boltzmann's constant in $[\mathrm{J} / \mathrm{K}]$

$\mathrm{m}_{\mathrm{e}} \quad=$ mass of electron $[\mathrm{kg}]$

$\phi \quad=$ work function of element in $[\mathrm{eV}]$

$\rho \quad=$ perveance [pervs]

$\mathrm{r}_{\mathrm{b}} \quad=$ radius of emitter $[\mathrm{m}]$

$\mathrm{T}=$ temperature $[\mathrm{K}]$

$\mathrm{T}_{\mathrm{o}} \quad=$ energy of emitted electrons $[\mathrm{eV}]$

$\mathrm{V}=$ plasma sheath gap potential $[\mathrm{V}]$

$\mathrm{V}_{\mathrm{emf}}=$ electro motive force [V]

$\Delta \mathrm{V}_{\mathrm{tc}} \quad=$ potential across the thermionic cathode [V]

$\mathrm{v}_{\text {orb }} \quad=$ orbital velocity with respect to local plasma $[\mathrm{m} / \mathrm{s}]$

$\mathrm{W} \quad=$ width of the emitter [m]

\section{Introduction}

Electrodynamic tethers (EDTs) are being considered as a propellantless propulsion technology for spacecraft in low Earth orbit. An orbiting tether system naturally orients along the local vertical due to gravity. Current flowing along the tether interacts with the Earth's magnetic field to provide thrust by the Lorentz force. To produce this current, we generally think of electrons being collected on one end of the tether and emitted at the other, using the ionosphere as the path to close the electrical circuite. This paper considers various electron emission methods for this purpose and the relative merits thereof.

There are three electron emission technologies usually considered: hollow cathode plasma contactors (HCPCs), thermionic cathodes (TCs), and field emitter arrays (FEA's). System level configurations are presented below and the relative costs and benefits discussed.

\section{Electron Emission Theory and Space Charge Limits}

In order to understand the physical effects involved in our system simulations, it is necessary to understand the basic mechanisms involved. The 3 electron emission techniques as well as general space-charge limits are discussed.

\footnotetext{
* Ph.D. Candidate, Electrical Engineering and Computer Science, 2455 Hayward Ave., AIAA Student Member

$\dagger$ Professor, Electrical Engineering and Space Systems, 2455 Hayward Ave., AIAA Associate Fellow
} 


\section{A. Thermionic Emission}

For the emission of electrons into a vacuum by a heated electronic conductor cathode, the emission current density, $J$, increases rapidly with increasing temperature; this is illustrated in Eq. (1), the Richardson-Dushman, or Richardson equation (here we assume typical values - $\phi$ is approximately $4.54 \mathrm{eV}$ and $\mathrm{A} \sim 120 \mathrm{~A} / \mathrm{cm}^{2}$ for tungsten).

$$
J=A T^{2} e^{-(\phi / k T)}
$$

$$
\Delta V_{t c}=\left[\frac{\eta \cdot I_{t}}{\rho}\right]^{2 / 3}
$$

TC electron emission will occur in one of two different modes: temperature or space charge limited (SCL) current flow. For temperature limited flow, every electron released from the cathode surface emitted (Eq. 1). If the cathode temperature could be increased, additional electrons could be emitted. In SCL electron current flow, there are so many electrons emitted from the cathode that not all are able to escape the near region of the surface due to space charge limits. An external applied bias potential is required to extract charge. This can occur if an accelerated grid is used. Eq. (2) shows what potential is needed across the grid in order to emit a certain current entering the device. ${ }^{2,3}$

\section{B. Field Emission}

In field emission cathodes, electrons tunnel through a potential barrier, rather than escaping over it as in thermionic emission or photoemission. In the presence of a strong electric field $\mathrm{F}$ at the surface. Electrons are extracted from the conduction band with a current density given by the Fowler-Nordheim equation in Eq. (3). ${ }^{6}$

$$
J=B \cdot F^{2} \cdot e^{-C / F}
$$

In the following analysis, typical constants yielded for Spindt-type cathodes include: $\mathrm{B}=3.14 \times 10^{-7} \mathrm{~A} / \mathrm{V}^{2}$ and $\mathrm{C}=771 \mathrm{~V}$. (information c/o Stanford Research Institute). An accelerating structure is typically placed in close proximity with the emitting material as in Fig. 1. To achieve the high surface electric fields required for field emission, the emitting material might consist of a range of materials from semiconductor fabricated molybdenum tips with integrated gates, to a plate of randomly distributed carbon nanotubes with a separate gate structure suspended above. Close (micron scale) proximity between the emitter and gate, combined with natural or artificial focusing structures efficiently provide the high field strengths required for emission with relatively low applied voltage, and low power. ${ }^{6}$

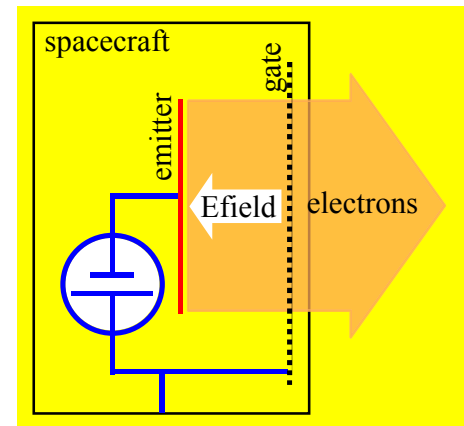

Figure 1: Electrical diagram of the basic field emission concept

\section{Hollow Cathodes}

Hollow cathodes emit ions or electrons by ionizing a consumable gas supply to create a high density plasma plume in contact with the surrounding plasma. One type of hollow cathode consists of a metal tube lined with a sintered tungsten insert capped at one end by a plate with a small orifice, as shown in Fig. 3. Electrons are emitted from the barium oxide impregnated insert by thermionic emission. Propellant gas, typically xenon, flows into the tube and exits, partially ionized, out of the orifice. Electrons flow from the insert region, through the orifice plasma to the keeper and other anode surfaces.

In electron emission mode the electrons from the plasma contactor principally carry the current while the contactor ions principally help provide a neutral plume region that allows for a larger "contact" area with the surrounding plasma. In the contactor plasma plume, the electron density is approximately equal to the ion density. The higher energy electrons stream through the slowly expanding ion cloud, while the lower energy electrons are trapped within the cloud by the keeper potential. The high electron velocities lead to electron currents much greater than Xenon ion currents. Below the electron emission saturation limit the contactor acts as a bipolar emissive probe. Each outgoing ion generated by an electron allows a number of electrons to be emitted, which is approximately equal to the square root of the ratio of the ion to electron masses. 


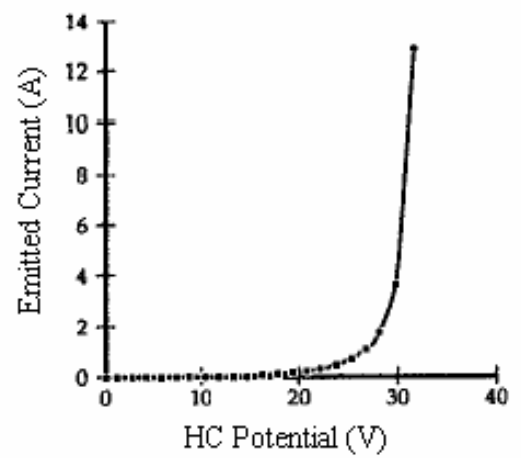

Figure 2: I-V Characteristic curve for a Hollow Cathode

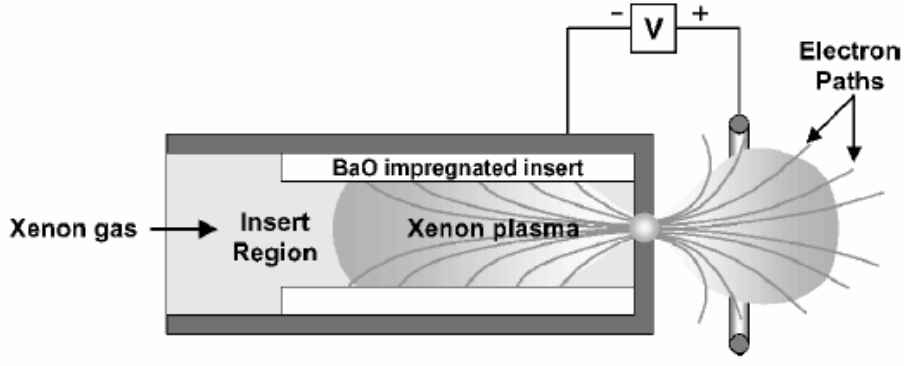

Figure 3: Schematic of a Hollow Cathode System

It can be seen in Fig. 2 what a typical I-V curve looks like for a hollow cathode. Given a certain keeper geometry, ion flow rate, and potential, the profile can be determined. ${ }^{8-10}$

\section{Space Charge Limit}

In any application where electrons are emitted across a vacuum gap there is a maximum allowable current for a given bias due to the self repulsion of the electron beam. Classical space charge limits depend on current density, gap width, gap potentials, geometry, and on initial kinetic energy in the Child-Langmuir Law. Here, the "gap" is an ion-rich plasma sheath transitioning from the background plasma to the spacecraft surface. The presence of ions in the gap (sheath) improves space charge constraints as the ions act to neutralize electron charge. The one-dimensional classical (vacuum gap) ChildLangmuir Law current density limit (in MKS units) is given in Eq. (4) which we multiply by the area of the planar emitter. ${ }^{11}$

$$
I_{C L}(1)=\frac{4 \varepsilon_{o}}{9 e} \sqrt{\frac{2}{m_{e}}} \frac{T_{o}^{3 / 2}}{D^{2}}\left[1+\sqrt{1+\frac{e V}{T_{o}}}\right]^{3} A_{e}
$$

Here, we will assume that the plasma sheath gap potential is within a few $\mathrm{eV}$ of the local plasma potential, and the sheath width is on the order of a few Debye lengths. These assumptions are consistent with the situation of an electrically isolated (floating) spacecraft or subsystem. The sheath dimension is in general set by the sheath potential, background plasma density, temperature, and geometry. In addition, because of the low electron temperature of ionospheric plasmas in ED tether applications, it is possible to assume $\mathrm{V}<<\mathrm{T}_{\mathrm{o}}$ in Eq. (4).

In going from a $1 \mathrm{~d}$ to a $2 \mathrm{~d}$ configuration, Eq. (4) can be increased by a multiplicative term if the beam of electrons can expand laterally (from the direction of beam propagation) into regions of no or less electron charge. The multiplicative term has been determined for when the electrons expand in one direction from a long emitter strip of width, W, and gap, D (see Fig. 4a). This 2-d space charge limit determined by computer simulation can be seen in Eq. (5). ${ }^{11}$

$$
\frac{J_{C L}(2)}{J_{C L}(1)}=1+\frac{0.3145}{W / D}-\frac{0.0004}{(W / D)^{2}}
$$

$$
\frac{J_{C L}(3)}{J_{C L}(1)}=\frac{\left[r_{b}^{2}+(D / 2)^{2}\right]}{r_{b}^{2}}=\left[1+\left(D / 2 r_{b}\right)^{2}\right]
$$

An enhancement over the 1-d classical Child-Langmuir limit $\left(\mathrm{T}_{\mathrm{o}}=0\right)$ is possible from a narrow pencil beam (i.e., expansion in two lateral directions) generated by an emitter of radius, $\mathrm{r}_{\mathrm{b}}$, and gap, $\mathrm{D}$, according to the 3-d Space charge limit equation in Eq. (6), where it is assumed that $\mathrm{r}<\mathrm{D}$ (see Fig. 4b). ${ }^{13}$ It is also noted that multiple pencil beams can be placed in parallel, with each experiencing the enhancement of Eq. (6), provided that the center to center beam spacing is large with respect to D. To estimate a threshold for space charge limited current flow, we will use Eq. (4) with the 3-d addition from Eq. (6). This calculation results in the determination of the current emitted after the space charge limit.

Further detailed analysis could also address the following non-idealities: For example, the presence of the emitted electron charge in the sheath could distort local sheath conditions. Besides transit of the electron beam across an ion-rich sheath, its penetration into and accommodation by the plasma must be considered. The larger the density of the electron beam relative to the background plasma density, the stronger the space charge effects will be even in the plasma. Thus, this situation will likely be most acute for ED tether applications where emitted currents are high and background plasma densities are lower. ${ }^{14}$ 


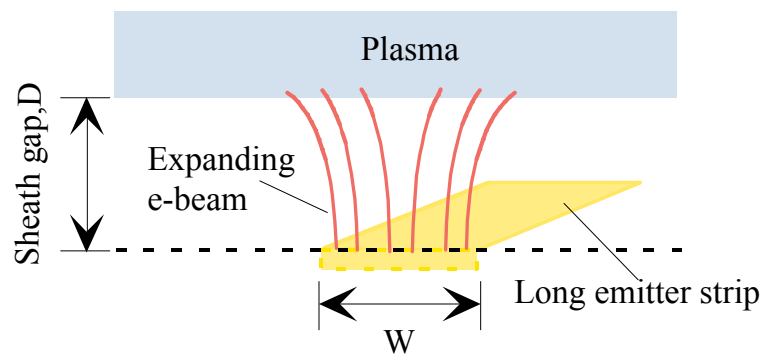

(a)

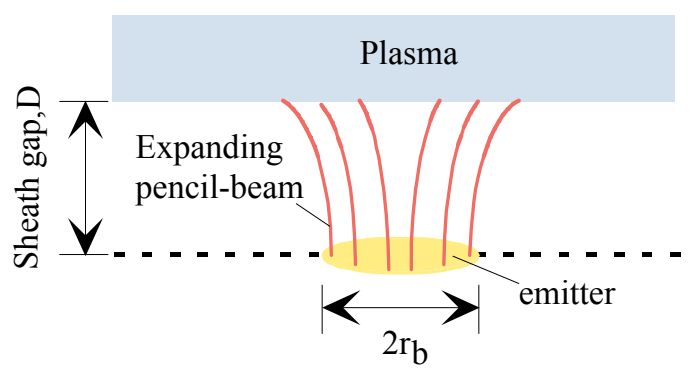

(b)

Figure 4: Strip (a) and pencil beam (b) emitters

\section{ED Tethers: System Integration}

\section{A. Tether Fundamentals}

A tether EMF is generated by Eq. (7) as the satellite orbits the Earth. In self-powered mode (de-orbit mode) this EMF can be utilized by the tether system to perform various functions: charge batteries, emit electrons at the emitting end, and drive the current through the tether. In boost mode on-board power supplies must overcome this motional EMF to provide bias for current collection, electron emission, and tether resistive losses.

$$
\begin{gathered}
V_{\text {emf }}=\left(v_{\text {orb }} \times B_{\text {North }}\right) \cdot d l \\
d F=d l \cdot I_{t} \times B_{\text {North }}
\end{gathered}
$$

Take, for example, the NASA ProSEDS mission. The Earth's magnetic field is approximately $0.18-0.32$ gauss in LEO, and the orbital velocity with respect to the local plasma is about $7500 \mathrm{~m} / \mathrm{s}$ at $300-\mathrm{km}$ altitude. This results in a $\mathrm{V}_{\text {emf }}$ of a range of $35-250 \mathrm{~V} / \mathrm{km}$ along the length of the tether (The ProSEDS conducting tether was 5 $\mathrm{km}$ long). This established EMF dictates the potential difference across the bare tether which controls where electrons are collected and or repelled. Here a de-boost tether has a setup that allows for electrons to be collected on the positively biased upper section of the bare tether, and returned to the ionosphere at the lower end. This flow of electrons through the length of the tether moving across the Earth's magnetic field creates a force that produces a drag thrust that helps de-orbit the system as given by the Eq: (8). The boost mode is similar to the de-orbit mode except for

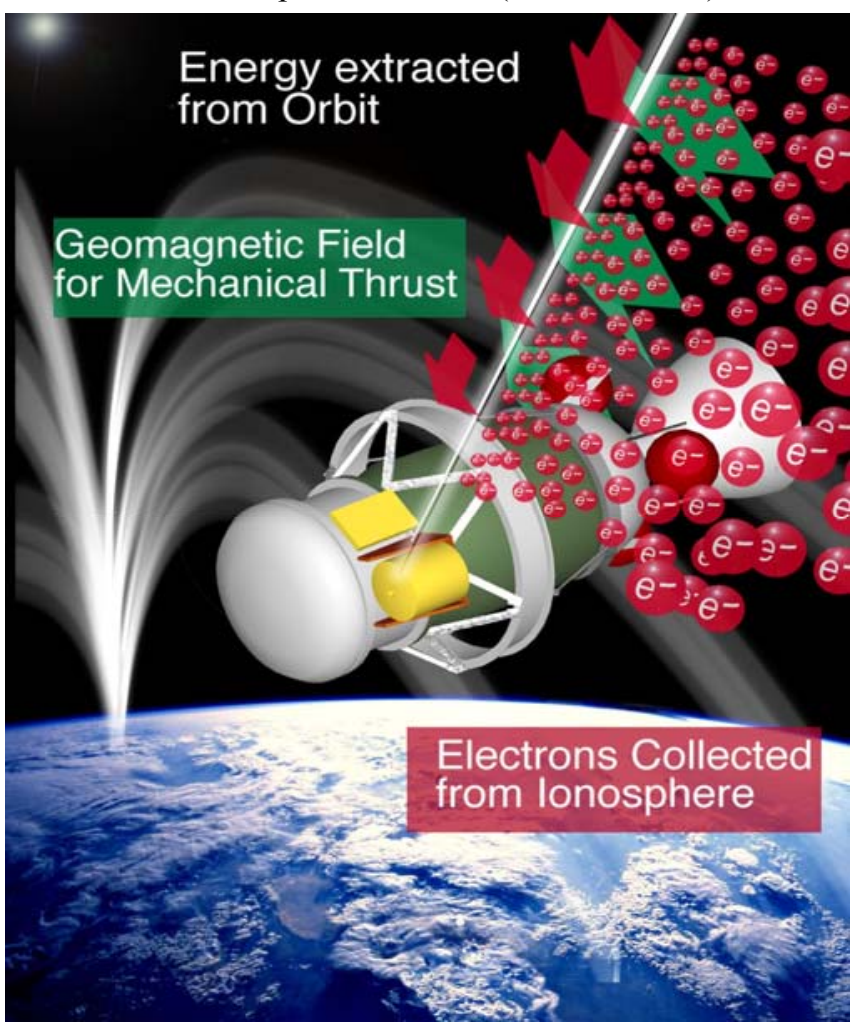

Figure 5: Illustration of the EDT concept the fact that an HVPS is also inserted in series with the tether and creates a potential difference greater than the $\mathrm{V}_{\text {emf. }}$ This drives the current the opposite direction, which in turn causes the upper end to be negatively charged, while the lower end is now positively charged.

\section{B. System Requirements}

In every ED tether mission there will be a number of conditions that will be encountered (e.g. the plasma and pressure environments, emission currents, electron emission energy, leakage current, and lifetime.

The electron emitter must be able to operate with the expected ambient environment pressure and species plus outgassing from the spacecraft $\left(<10^{-7}\right.$ Torr). Some systems must be able to survive pressure exposures to $10^{-3}$ Torr (e.g. due to attitude control thrusters such as hydrazine and other spacecraft effluents).

Arrays of electron emitters will need to emit peak current that can range from $<100 \mathrm{~mA}$ up to 10 's of amps depending on the specific application. For example, atmospheric drag make-up of a large spacecraft could require well less than 1 A while rapid de-orbit of a spent stage or drag make-up of the space station may benefit from currents as much as 
10 A. Emission of this level of current requires special consideration of space charge effects which will limit maximum allowed current densities while spacecraft surface area utilization will place a lower limit. For example, for a small satellite de-boost application emission area might need to be constrained to some number at or below $100 \mathrm{~cm}^{2}$ while a large spacecraft boost system may be able to accept current emission areas many times larger. For these emission areas, operation should be below space charge limited current flow levels (See space charge limit section for further discussion).

Low leakage current of the electron emitters is required to ensure efficient cathode operation and since ED tethers use similar systems the requirements here are identical to that described above (e.g. FEAC gate current must be less than 1\% is best for conservative operation).

Finally, a typical ED tether system is expected to operate for durations ranging from a few weeks of continuous operation to several years at a 50\% duty cycle. Typical lifetimes requirements are between 1,000 hours and 13,000 hours depending on the application. For some applications the unit might be expected to remain dormant on the spacecraft for some 5 to 7 years before operation. ${ }^{14}$

\section{Configurations}

There are three configurations considered for connecting the electron emitter to the tether circuit as shown in Fig. 6. They are identified as: (a) basic grounded-emitter, (b) basic grounded-gate, and (c) series bias - grounded-gate. The grounded-emitter (Fig. 6a) configuration effectively isolates the tether and high-voltage power supply (HVPS) circuit from the electron emitter. The electron emitter bias is exclusively set by the 'emitter bias' supply. However, the gate is at a positive potential with respect to the surrounding space plasma that can attract electrons from the plasma drawing current through the power supply. ${ }^{16}$ A grounded-gate configuration is shown in both Fig's $6 \mathrm{~b}$ and $6 \mathrm{c}$. The grounded-gate configuration allows all external structures, including the field emission gate itself, to be held at the floating potential of the spacecraft, which should minimize the disturbance in the surrounding plasma when the electron emitter is providing all of the tether current. The Fig. $6 \mathrm{~b}$ configuration has the draw back that if the electron emitter can not provide all of the tether current, then the spacecraft potential will be pulled negative and possibly substantially negative through the electron 'emitter bias' supply; a technical challenge to adequately protect the field emitters in that situation. Our initial assessment, therefore, is that the series bias grounded-gate configuration in Fig. 6c will be the best, most robust option to be utilized for most EDT systems. The drawback to this configuration is that the emitter bias supply now must source power although there is a corresponding reduction in the power provided by the HVPS and overall power requirements remain unchanged.

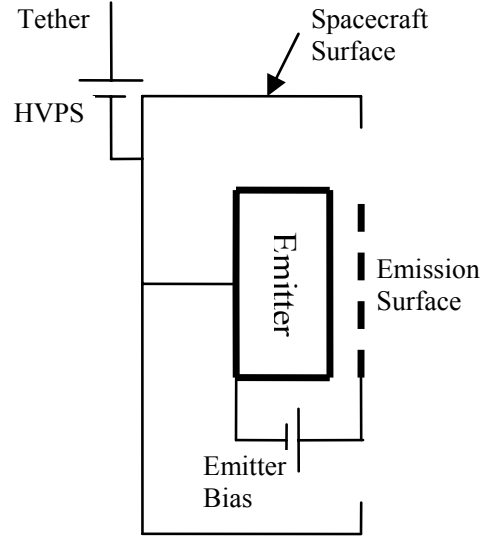

(a)

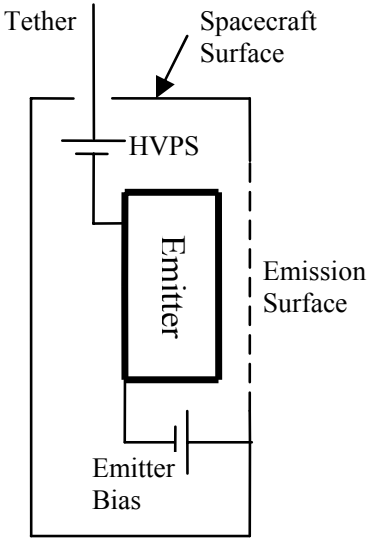

(b)

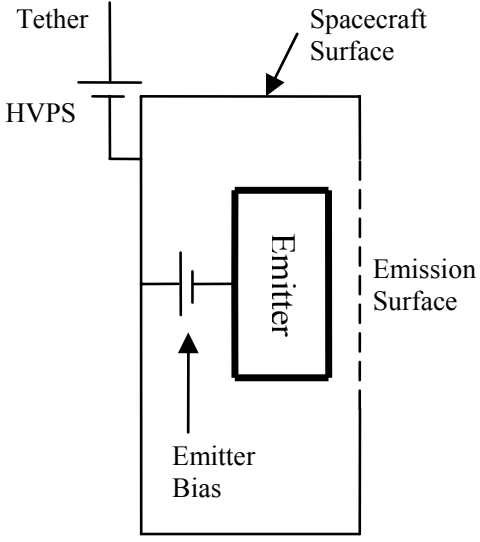

(c)

Figure 6: Possible electrical configurations of the electron emitter with the tether and high voltage power supply (HVPS): Grounded tip/emitter (a), grounded-gate (b) and grounded-gate, isolated tether (c) configurations.

When FEA's and TC's are used they have to emit the electrons as close to floating potential as possible in order to be the most efficient. ${ }^{17}$ The grounded-gate configurations allow this to occur. The spacecraft surface is at the floating potential in these cases, provided all the current from the tether is being emitted through the emitter without any coming back from space charge limits. The hollow cathode has a phenomenon called a double sheath which makes the emitted electrons cross two boundary layers, the emitted xenon and the normal plasma sheath. The most accurate way to model this is through (6a). Here the spacecraft body is forced negative by the xenon plasma released from the hollow cathode. 


\section{System Response / Precautions}

Numerous environmental conditions will cause the dynamics of the EDT system to fluctuate dramatically. As a result the potentials and currents will be constantly changing. Each electron emitter will behave differently under such varying conditions, and as a result the system must be understood and controlled for all such cases.

Outputs from instruments that measure return current and the spacecraft's floating potential could be used by the electron emitter to make decisions about emission current. This feedback loop, which balances incoming and outgoing current, controls the spacecraft potential and keeps it near neutral. Thus, the electron emitter operates at optimum efficiency for whatever current level the tether power system is able to provide. The electron emitter will need to automatically and stably respond in different ways for conditions when there is too much and too little emitted current.

These precautionary measures need to be in place not only to ensure the system runs efficiently, but to prevent damaging the electron emission devices. The TC is only meant to run up to a maximum potential and maximum current depending on its design parameters, however these are often relatively high conditions. Similar situations could happen to the FEA. Above approximately 120 volts for a Spindt-type emitter the array may be damaged. Finally, the hollow cathode is able to emit a much higher current without being damaged.

\section{System Simulations}

\section{A. Simulation System Setup}

The physical setup of the simulated EDT system was chosen to be similar to a past proposed mission called ProSEDS. Table 1 describes the statistics of the physical setup.

\begin{tabular}{|c|c|c|c|}
\hline & Delta 2 Payload & Tether Section & Endmass / e- emitter \\
\hline Surface Area $(\mathrm{SA})\left[\mathrm{m}^{2}\right]$ & 8.08 & 6.7568 & 0.7854 \\
\hline Total Section Mass $[\mathrm{kg}]$ & 980 & 55 & 20 \\
\hline \hline & Total Mass $=1055 \mathrm{~kg}$ & Total SA $=15.622 \mathrm{~m}^{2}$ & Ballistic Coeff. $=30.697$ \\
\hline
\end{tabular}

Table 1: System Setup Statistics

The first five kilometers of the tether was conducting (multi-stranded aluminum), with an overall radius of $0.6 \mathrm{~mm}$, while the rest was non-conducting, with a radius of $0.75 \mathrm{~mm}$. This was chosen because a static case was needed to test all the conditions at varying plasma densities. For high densities the most desirable de-boost system setup would be to have a longer conducting section because that entire section would be positively charged and collecting electrons. A longer conducting section would allow the collection of more electrons thus enhancing the amount of de-boosting force on the system. On the other hand, for cases of low electron densities the positively charged section of the tether would end only a fraction of the distance along the tether. This would cause the rest of the conducting tether after that point to negatively charged, and thus lose current and reduce the total de-boosting force on the system. The most desirable boosting system setup for dense plasma would be one that had less of the conducting wire exposed because collection is being forced to occur on the opposite end of the tether. Likewise, a low plasma density boosting case would require more exposed conducting tether.

The next aspect that had to be decided was dates representing the extreme cases that the system might encounter. The dates selected were January 1, 2006 and July 15, 2001, solar min, night time and solar max, day time, respectively. The atmospheric data was then acquired for those dates for various altitudes at a latitude of 0 degrees. This data can be seen in Table 2.,4,5,7 The EMF was calculated using Equation 7 where $\mathrm{dl}$ is $5005 \mathrm{~m}$. The orientation of the tether for these simulations is always a straight and perpendicular to Earths magnetic field.

\begin{tabular}{|c|c|c|c|c|c|c|c|c|}
\hline $\begin{array}{c}\text { Altitude } \\
{[\mathrm{km}]}\end{array}$ & $\mathrm{B}_{\text {North }}[\mathrm{nT}]$ & EMF $[\mathrm{V}]$ & $\mathrm{v}_{\text {orb }}[\mathrm{m} / \mathrm{s}]$ & $\begin{array}{c}\text { Ion Temp. } \\
{[\mathrm{eV}]}\end{array}$ & $\begin{array}{c}\text { Ele. Temp. } \\
{[\mathrm{eV}]}\end{array}$ & $\mathrm{Ne}\left[\# / \mathrm{m}^{\wedge} 3\right]$ & $\begin{array}{c}\text { Avg. Mol. } \\
\text { Wt. }\end{array}$ & $\begin{array}{c}\text { Atm. Drag } \\
{[\mathrm{N}]}\end{array}$ \\
\hline 200 & 25522 & 930 & 7282 & 0.06 & 0.06 & $4.20 \mathrm{E}+09$ & 24.96 & $2.28 \mathrm{E}-01$ \\
250 & 28067 & 1022 & 7275 & 0.06 & 0.07 & $4.28 \mathrm{E}+10$ & 20.40 & $3.52 \mathrm{E}-02$ \\
300 & 27160 & 985 & 7243 & 0.06 & 0.06 & $4.61 \mathrm{E}+10$ & 16.58 & $6.85 \mathrm{E}-03$ \\
400 & 26300 & 945 & 7176 & 0.07 & 0.08 & $3.55 \mathrm{E}+10$ & 15.70 & $4.05 \mathrm{E}-04$ \\
500 & 25064 & 892 & 7112 & 0.07 & 0.08 & $2.57 \mathrm{E}+10$ & 14.92 & $3.57 \mathrm{E}-05$ \\
750 & 22131 & 771 & 6958 & 0.08 & 0.09 & $1.76 \mathrm{E}+10$ & 8.48 & $2.07 \mathrm{E}-06$ \\
1000 & 19915 & 679 & 6810 & 0.09 & 0.09 & $1.64 \mathrm{E}+10$ & 2.53 & $6.31 \mathrm{E}-07$ \\
1500 & 16080 & 526 & 6534 & 0.08 & 0.08 & $1.63 \mathrm{E}+10$ & 1.19 & $1.54 \mathrm{E}-07$ \\
2000 & 13170 & 414 & 6279 & 0.11 & 0.11 & $1.64 \mathrm{E}+10$ & 1.19 & $7.09 \mathrm{E}-08$ \\
\hline
\end{tabular}

(a) 


\begin{tabular}{|c|c|c|c|c|c|c|c|c|}
\hline $\begin{array}{c}\text { Altitude } \\
{[\mathrm{km}]}\end{array}$ & B $_{\text {North }}[\mathrm{nT}]$ & EMF [V] & Vorb $_{\text {orm } / \mathrm{s}]}$ & $\begin{array}{c}\text { Ion Temp. } \\
{[\mathrm{eV}]}\end{array}$ & $\begin{array}{c}\text { Ele. Temp. } \\
{[\mathrm{eV}]}\end{array}$ & Ne [\#/m³] & $\begin{array}{c}\text { Avg. Mol. } \\
\text { Wt. [amu }]\end{array}$ & $\begin{array}{c}\text { Atm. Drag } \\
{[\mathrm{N}]}\end{array}$ \\
\hline 200 & 36192 & 1324 & 7309 & 0.08 & 0.12 & $2.23 \mathrm{E}+11$ & 18.96 & $3.93 \mathrm{E}-01$ \\
250 & 34920 & 1272 & 7275 & 0.08 & 0.17 & $7.51 \mathrm{E}+11$ & 16.70 & $9.82 \mathrm{E}-02$ \\
300 & 32770 & 1186 & 7233 & 0.09 & 0.20 & $1.18 \mathrm{E}+12$ & 16.30 & $3.27 \mathrm{E}-02$ \\
400 & 29490 & 1049 & 7109 & 0.10 & 0.10 & $1.21 \mathrm{E}+12$ & 13.87 & $5.95 \mathrm{E}-03$ \\
500 & 26932 & 945 & 7008 & 0.11 & 0.11 & $9.12 \mathrm{E}+11$ & 11.53 & $1.57 \mathrm{E}-03$ \\
750 & 23776 & 816 & 6858 & 0.15 & 0.15 & $1.76 \mathrm{E}+11$ & 4.11 & $6.91 \mathrm{E}-05$ \\
1000 & 21384 & 718 & 6712 & 0.18 & 0.18 & $1.14 \mathrm{E}+11$ & 2.17 & $5.96 \mathrm{E}-06$ \\
1500 & 17500 & 564 & 6440 & 0.24 & 0.24 & $1.07 \mathrm{E}+11$ & 1.31 & $7.08 \mathrm{E}-07$ \\
2000 & 14456 & 448 & 6189 & 0.28 & 0.28 & $1.07 \mathrm{E}+11$ & 1.31 & $2.15 \mathrm{E}-07$ \\
\hline
\end{tabular}

(b)

Table 2: The atmospheric conditions for a) January 1, 2006 (Solar Min, night time) and b) July 15, 2001 (Solar Max, day time) used in the Simulation

The emitters were then chosen to simulate common industry standard emitters. The one commonality between the TC and FEA was that the total emitter area was kept constant at $10 \mathrm{~cm}^{2}$. The area didn't matter for the $\mathrm{HC}$ as the one chosen was capable of emitting up to $25 \mathrm{~A}$ for a small emitter size. Also, in order to run the simulations the latest HC models had to be obtained. ${ }^{15,12}$ Table 3 contains the specifications for the three emitters being used in the simulation.

\begin{tabular}{|c|c|c|}
\hline Field Emitter Array & Thermionic Cathode & Hollow Cathode \\
\hline \hline \# of tips per $\mathrm{m}^{2}=1 \mathrm{E} 11$ & Perveance $[\mathrm{pervs}]=7.2 \mathrm{E}-6$ & Diameter of keeper $[\mathrm{m}]=0.0047$ \\
\hline Tip Efficiency $=0.1$ & Efficiency $=0.97$ & Molecular Weight of Xenon $=131.29$ \\
\hline Fowler-Nordheim $\mathrm{C}[\mathrm{V}]=771$ & Work Function $($ Tungsten) $[\mathrm{eV}]=4.54$ & Orifice density $\left[\right.$ particles $\left./ \mathrm{m}^{3}\right]=2 \mathrm{E} 20$ \\
\hline Fowler-Nordheim B $\left[\mathrm{A} / \mathrm{V}^{2}\right]=$ & Emission current limit $[\mathrm{A}]=10$ & $\begin{array}{c}\text { HC Orifice Emitted Ion Current }[\mathrm{A}]= \\
0.128\end{array}$ \\
\hline $3.14 \mathrm{E}-8$ & & HC Anode Potential $[\mathrm{V}]=26.5$ \\
\hline Max Potential $[\mathrm{V}]=120 \mathrm{~V}$ & Electron Gun Max Potential $[\mathrm{V}]=2000$ & HC Orifice Radius $[\mathrm{m}]=0.00138$ \\
\hline Area per emitter $\left[\mathrm{m}^{2}\right]=5 \mathrm{E}-5$ & Area per emitter $\left[\mathrm{m}^{2}\right]=3.33 \mathrm{E}-4$ & Source Electron Temp. $[\mathrm{eV}]=3.9$ \\
\hline Number of emitters in system $=20$ & Number of emitters in system $=3$ & Thickness of keeper $[\mathrm{m}]=2.4 \mathrm{E}-4$ \\
\hline & Emitter Type $=$ Spindt & Orifice exit to keeper $[\mathrm{m}]=2.4 \mathrm{E} 4$ \\
\hline & & Number of emitters in system $=1$ \\
\hline
\end{tabular}

Table 3: Electron emission physical constants

\section{B. Simulations}

The simulations ran compared the boosting or de-boosting force, the total power of the system consumed, and the efficiency. The variables involved in these tests were altitude, field emitter type, and the emitter potential. All solutions show what the system performance would be for a moment in time with the input conditions. Figures 7 and 8 give the results of the simulations. An important note about all of the boosting cases is that the High Voltage Power Supply (HVPS) was set to $2000 \mathrm{~V}$, and the resistance of the tether was set to $0.05 \mathrm{Ohms}$ per meter or $250.25 \mathrm{Ohms}$. The purpose of these plots was to show the most efficient way to get maximum thrust in a tether system. This means that all of the electrons that were collected through the tether by means of orbital motion limited collection were capable of being emitted at the floating potential. This fact also means that the system was not calculated to be as power efficient as possible.

The conditions listed earlier, mode C (Fig. 6c), and the user defined condition of mode B (Fig. 6b) for the FEA and TC were not displayed in the following figures. This is because in the case of the used defined condition any emitter potential other than the one solved for in the floating case would be much more inefficient. Any potential at the end that is not at floating will be a limiting factor for the system because it will require that the electrons have much more energy to cross it and be emitted. This limit would in turn reduce the amount of electrons that will be initially collected in the system by decreasing the starting positive potential at the anode end of the tether. Mode C (Fig. 6c) was not included primarily because it is still being analyzed.

The total power value displayed in Figures 7 and 8 can be equated with the following summations: Total Power (for the boost cases) $=$ Power of the HVPS \& Total Power (for the de-boost cases) $=$ Power of the EMF. The power efficiency is calculated by dividing the power of the EMF by the total power supply. 
The total power value displayed in Figures 8 is equated using the same formula without the Tether EMF Power. The remaining plotted values are self explanatory. The electron density played a major role in what effects occurred in the system and thus was included in the plots as well. Nearly every plot corresponds directly with the rise and fall of the electron density. Also, these results are given for both extreme atmospheric cases. The only time that the plasma density might be larger would be during a Coronal Mass Ejection (CME).

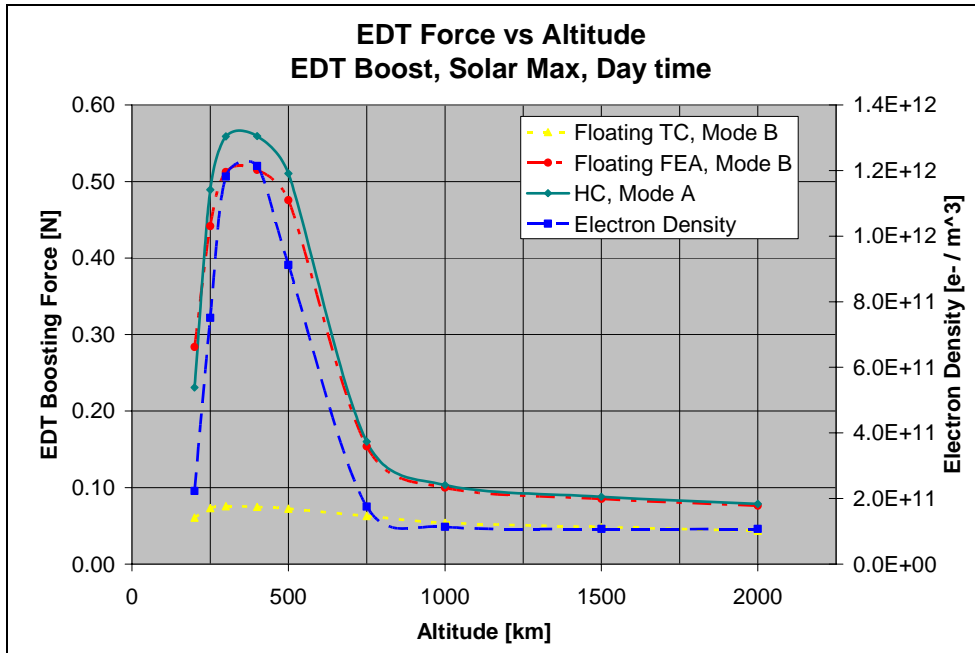

(a)

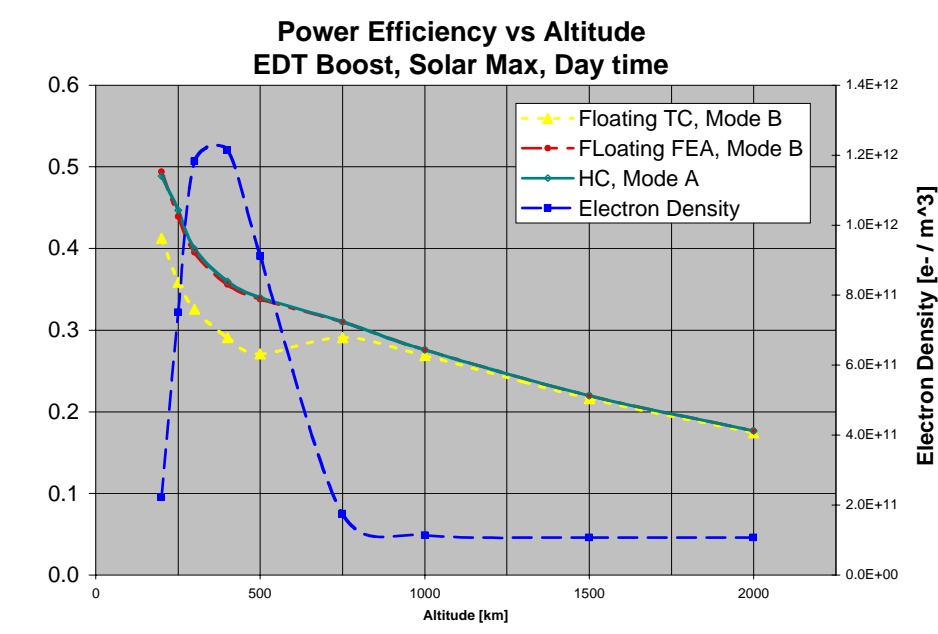

(c)

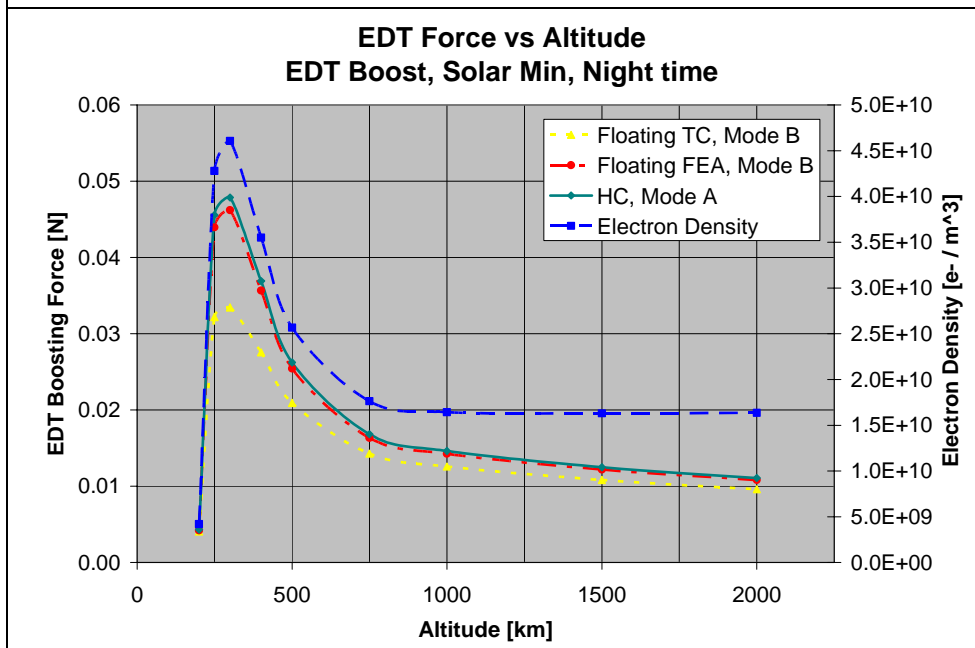

(e)

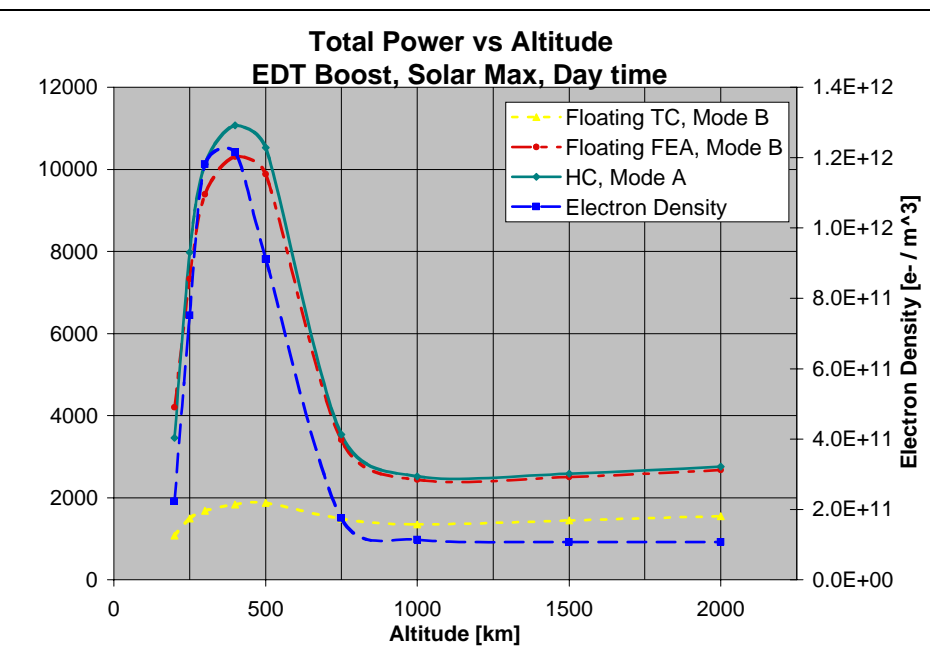

(b)

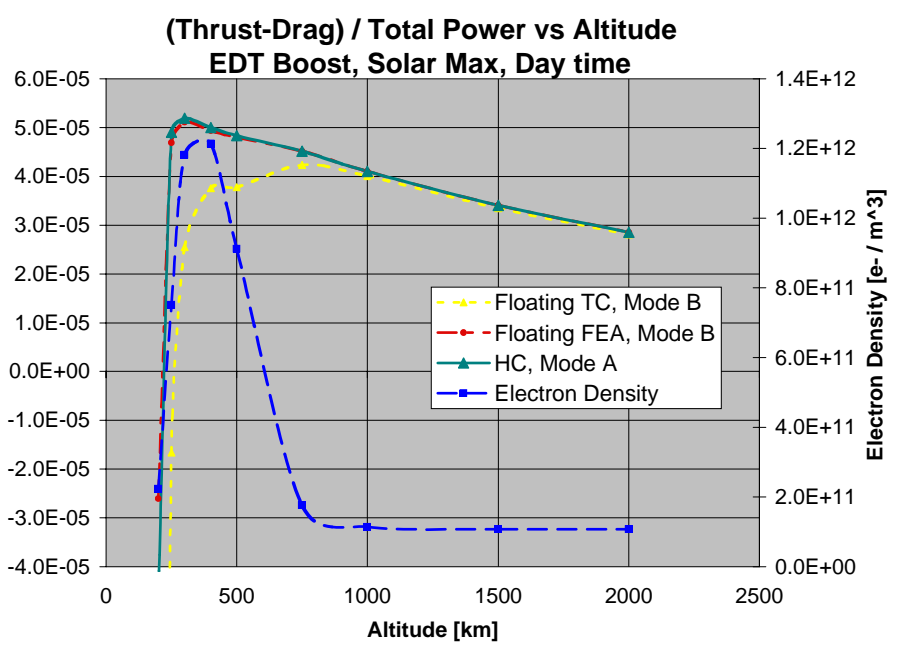

(d)

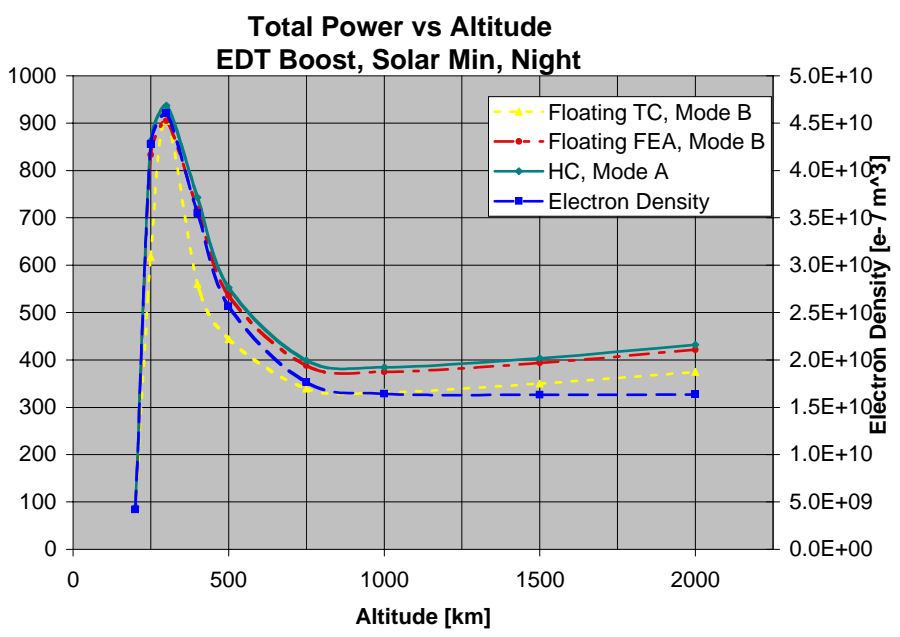

(f) 


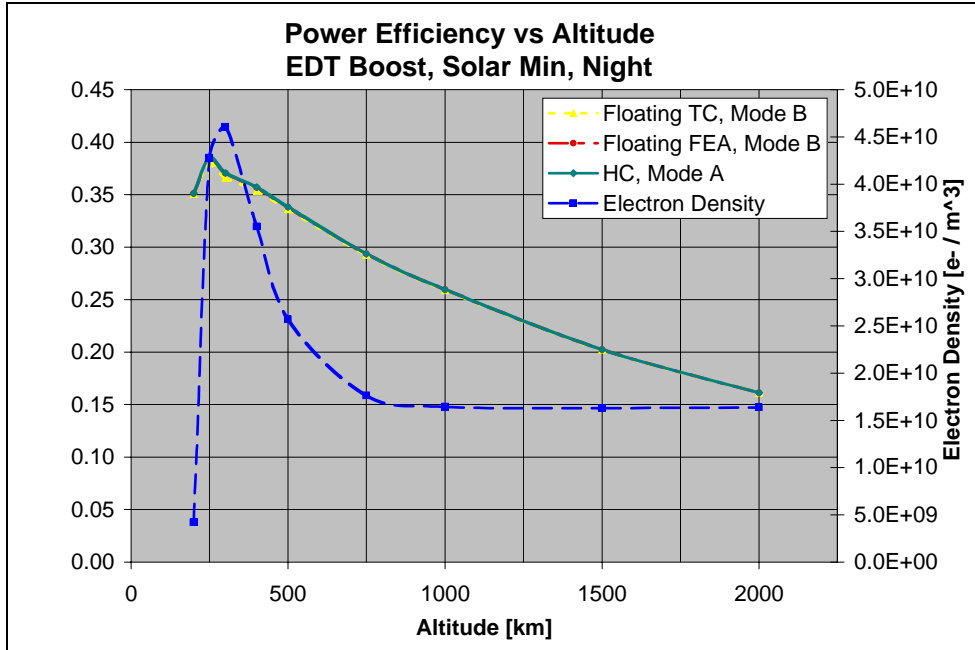

(g)

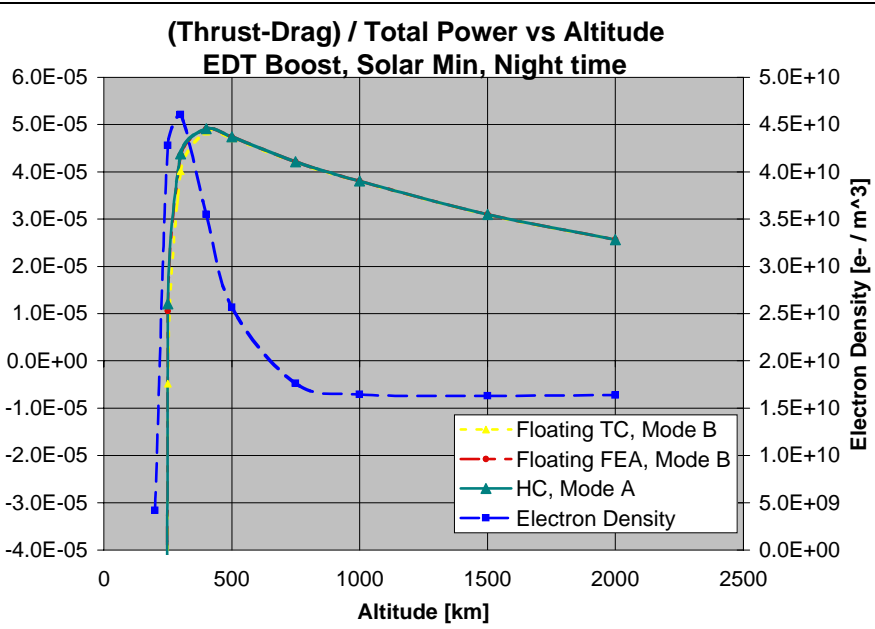

(h)

Figure 7: Results of the boosting cases where a), b), c), and d), are in solar max and d), e), (f), and g), are in solar min.

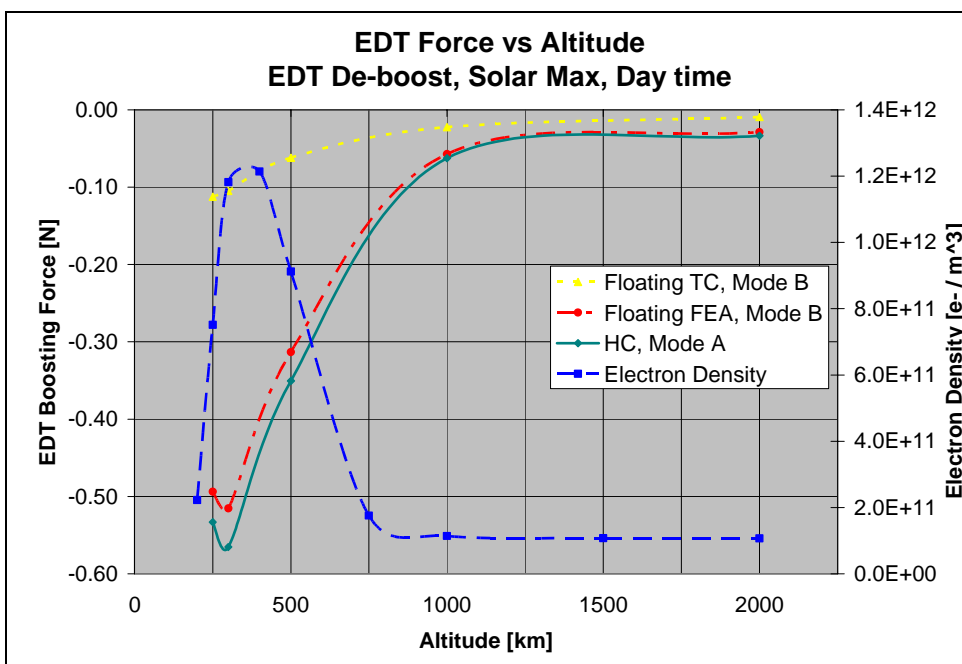

(a)

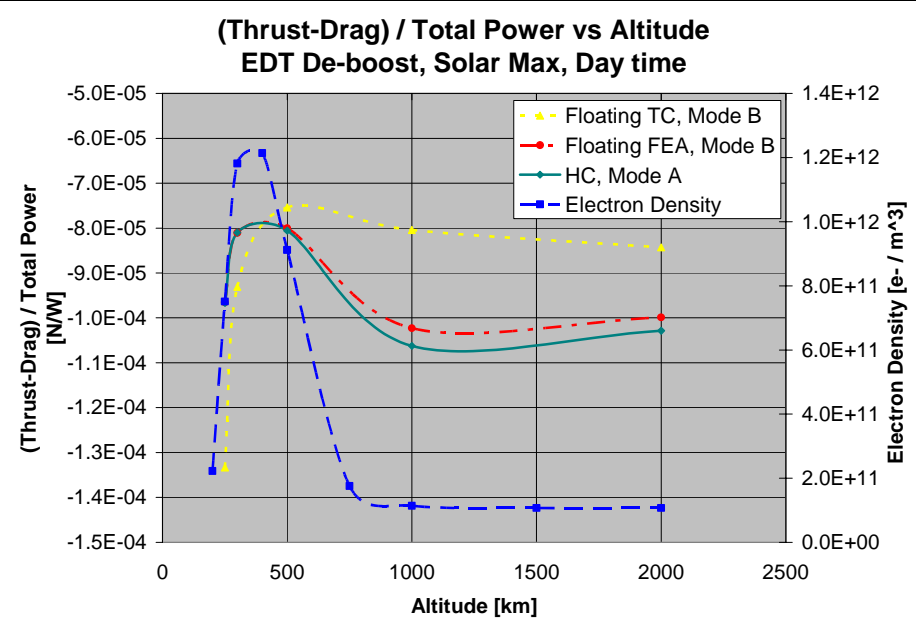

(c)

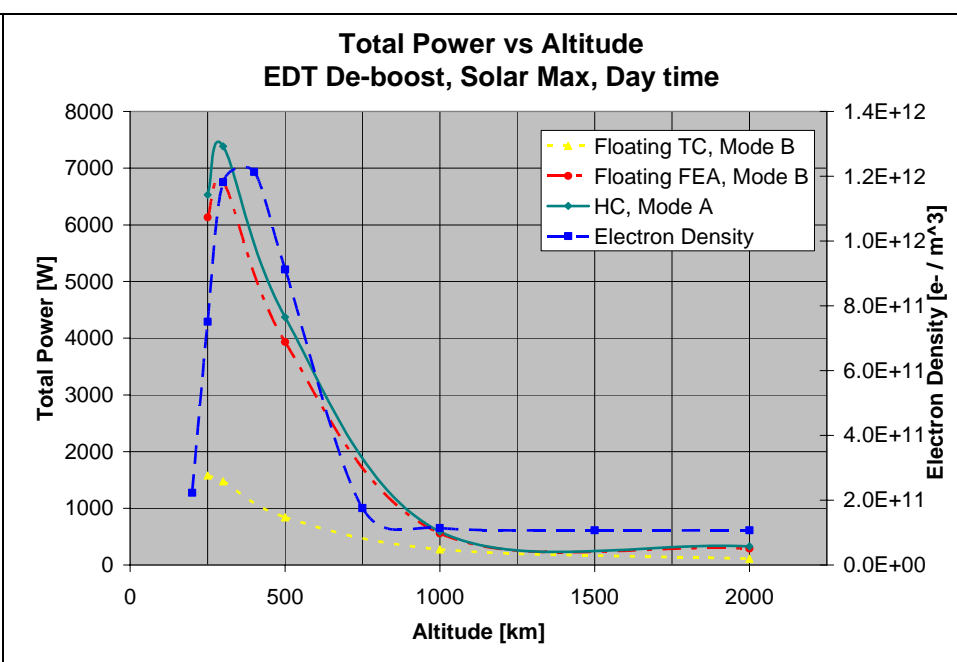

(b)

\section{EDT Force vs Altitude}

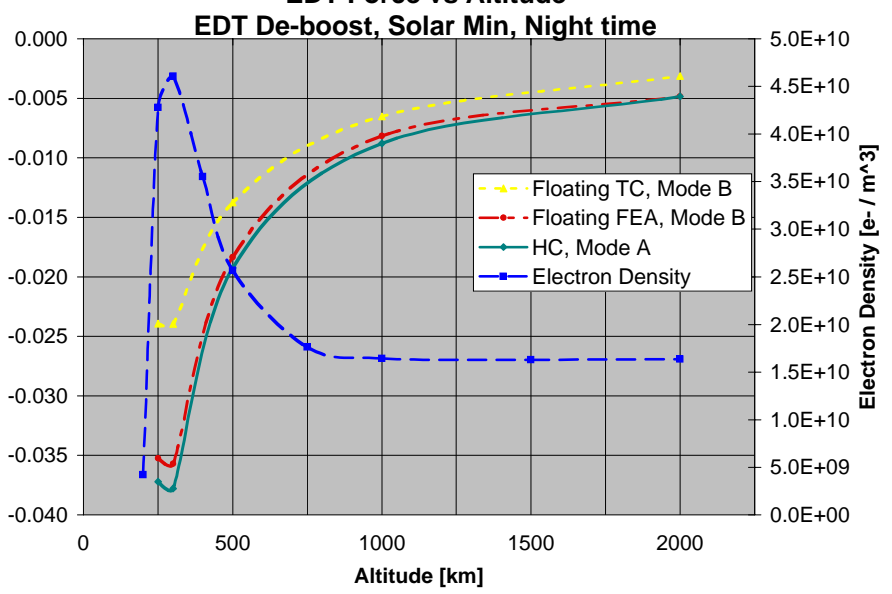

(d) 


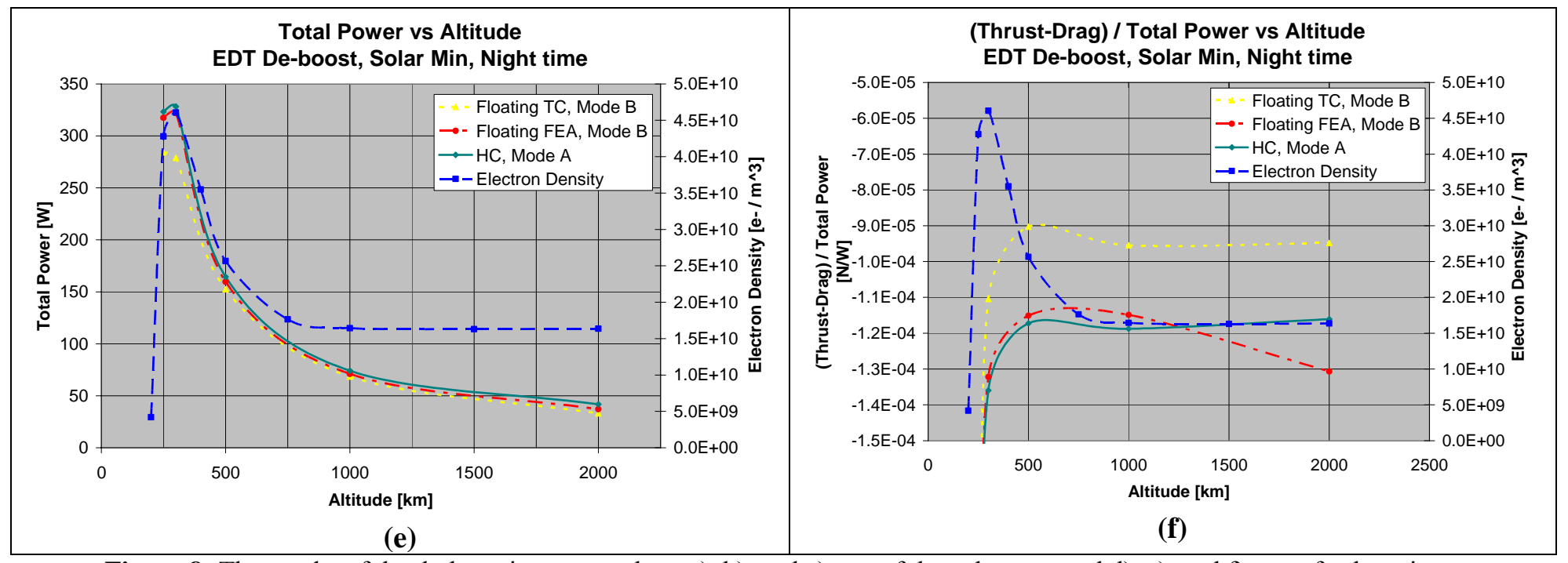

Figure 8: The results of the de-boosting cases where a), b), and c), are of the solar max and d), e), and f), are of solar min.

\section{Analysis}

As the system was being manipulated various mechanisms which controlled the cathode potential and total current collected became apparent. The number of electron emitters used determined how much potential was emitted. The fewer emitters there were, the less current could be emitted. In addition, the emitter max potential was the most the device was capable of emitting and as a result capped the amount of electrons that could be collected by the anode and tether. Another thing that prevented achieving floating potential was the space charge limit on the system. The smaller the emitter, the fewer the amount of electrons that could escape through the limit.

Figure $7 \mathrm{a}$ and $7 \mathrm{e}$ show the maximum amount of boosting force that an EDT system could acquire using each of the electron emission devices. In these figures it can be seen that the $\mathrm{HC}$ produces the greatest thrust at $\sim 0.56 \mathrm{~N}$, followed closely behind by the FEA at $\sim 0.51 \mathrm{~N}$. The TC produces almost 7.5 times less thrust during the solar max case than the other devices at $\sim 0.076 \mathrm{~N}$ and only about $30 \%$ less in the solar min case. The reason that the HC was so much less than the other emitters in the max density case was because of the number of emitters. There was constant surface area between the FEA and TC, but since the FEA's had so many more emitters the total current emitted was much less for the TC.

Figure $7 \mathrm{~b}, 7 \mathrm{c}$, and $7 \mathrm{~d}$ show similar trends to that of $7 \mathrm{a}$. The solar max case is limiting the effectiveness of the TC because there is so much more current that can be emitted in the system where only $3 \mathrm{TC}$ emitters are not enough. Similarly, Figure $7 \mathrm{f}$ has the same trend as Figure 7e in that the $\mathrm{HC}$ uses the most power, followed closely behind by the FEA and then the TC. Figures $7 \mathrm{~g}$ and $7 \mathrm{~h}$ show how the efficiencies between all the analyses at the solar min are identical.

It should be noted that In Figure $7 \mathrm{c}$ and $7 \mathrm{~d}$ there is an interesting phenomenon that occurs around the maximum density. A dip in the curve occurs, which at this point is still being investigated.

Figure 8 has identical trends where the HC is the strongest followed closely by the FEA and then the TC's behind that. The trends are similar to that of the boosting cases except the EDT force and Thrust - Drag over Power figures are inversely proportion to the electron density. This makes sense because in the de-boosting cases the EDT force is in the same direction as the drag force. Also, the phenomenon where there was not enough TC emitters and as a result less current was emitted, occurs again in the de-boosting case. Something that was not seen in the boosting case is the fact that the FEA case is more efficient than all the emitters above approximately $1300 \mathrm{~km}$ in altitude. In addition, the TC is the most efficient method until $400 \mathrm{~km}$ in the high density case.

\section{Conclusion}

Many aspects of each mission play a major role when deciding how to design the proper EDT system. One of the greatest factors is the proper electron emission device to use. It is clear that if FEA's prove reliable they will most likely be utilized into most of the future missions involving electron emission, especially EDT missions. While HCPC's are still a very efficient and useful technology the fact that they use propellant may deter many missions from using it when other technologies exist that do not use propellant. Future work will be done analyzing more aspects of EDT missions and cases where various configurations will be used. Many more tests will need to be conducted in order to fully show the trends that are seen in Figures 7 and 8. Particular aspects of interest will be looking at momentum transfer technologies. 


\section{References}

[1] McGuire, Robert, "International Reference Ionosphere - IRI-2001", http://nssdc.gsfc.nasa.gov/space/model/models/iri.html, last modified April 20, 2004.

[2] Dobrowolny, M., and Stone, N.H., "A Tecnical Overview of TSS-1: the First Tethered-Satellite System Mission," Il Nuovo Cimento Della Societa Italiana Di Fisica, Vol. 17C, No. 1, 1994, pp. 1-12.

[3] Bonifazi, C., Svelto, F., and Sabbagh, J., "TSS Core Equipment. I. - Electrodynamic Package and Rational for Sydtem Electrodynamic Analysis." Il Nuovo Cimento Della Societa Italiana Di Fisica, Vol. 17C, No. 1, 1994, pp. 13-47.

[4] McGuire, Robert, "DGRF/IGRF Geomagnetic Field Model 1945 - 2010 and Related Parameters", http://nssdc.gsfc.nasa.gov/space/model/models/igrf.html, last modified May 1, 2004.

[5] Bilitza, Dieter, "MSIS Model 1986", http://nssdc.gsfc.nasa.gov/space/model/atmos/msis.html, last modified July 10, 1996.

[6] Gomer, R., "Field Emission," in AccessScience@,Mcgraw-Hill, http://80www.accessscience.com.proxy.lib.umich.edu/serverjava/Arknoid/science/AS/Encyclopedia/2/25/Est 256200 frameset.html, last modified: January 28, 2002.

[7] Bilitza, Dieter, “International Reference Ionosphere (IRI) 1990”, ftp://nssdcftp.gsfc.nasa.gov/models/ionospheric/iri/, last modified November, 1991.

[8] Katz, I., Lilley, J. R. Jr., and Greb, A., "Plasma Turbulence Enhanced Current Collection: Results from the Plasma Motor Generator Electrodynamic Tether Flight," Journal of Geophysical Research, Vol. 100, No. A2, 1995, pp. 1687-1690.

[9] Katz, I., Anderson, J.R., and Polk, J.E., " One-Dimensional Hollow Cathode Model," Journal of Propulsion and Power, Vol. 19, No. 4, 2003, pp. 595-600.

[10] Parks, D.E., Katz, I., and Buchholtz, B., "Expansion and electron emission characteristics of a hollow-cathode plasma contactor," Journal of Applied Physics, Vol. 74, No. 12, 2003, pp. 7094-7100.

[11] Luginsland, J.W., McGee, S., and Lau, Y.Y., " Virtual Cathode Formation Due to Electromagnetic Transients," IEEE Transactions on Plasma Science, Vol. 26, No. 3, 1998, pp. 901-904.

[12] Science Applications International Corporation (SAIC), "Chapter 12.3 - Plasma Contactors" Environment Work Bench User's Reference Manual, March 2003, pp. 12.11 - 12.23.

[13] Humphries, S., Jr., "Charged Particle Beams," John Wiley \& Sons, Inc., Ney York, 1990, pp. 834

[14] Gilchrist, B.E., Gallimore, A.D., and Jensen, K.L., "Field-Emitter Array Cathodes (FEACs) for Space-Based Applications: An Enabling Technology," Not Published, University of Michigan, 2001.

[15] Domonkos, Matthew Thomas, "Evaluation of Low-Current Orificed Hollow Cathodes," University of Michigan Ph.D., 1999, pp. 1-155.

[16] Morris, D., Gilchrist, B., and Gallimore, A., "Integration of Field Emitter Arrays into Spacecraft Systems," Space Technology and Applications International Forum, AIAA, 2002, pp. 393-400.

[17] Morris, D., and Gilchrist, B., "Electron Field Emission and the Space Charge Limit: Techniques and Tradeoffs," Joint Propulsion Conference, AIAA, 2003, pp. 1-9. 